\title{
In silico Study of Potential Non-oxime Reactivator for Sarin- inhibited Human Acetylcholinesterase
}

\author{
Rauda A. Mohamed ${ }^{1,2}$, Keat Khim Ong ${ }^{2,4}$, Norhana Abdul Halim ${ }^{3}$, Noor Azilah \\ Mohd Kasim ${ }^{2,4}$, Siti Aminah Mohd Noor,3, Victor Feizal Knight' ${ }^{2}$, Rabbani \\ Muhamad $^{1}$ and Wan Md Zin Wan Yunus ${ }^{1,2 *}$
}

${ }^{1}$ Centre for Tropicalization, National Defence University of Malaysia, Kuala Lumpur, 57000, Malaysia ${ }^{2}$ Centre for Chemical Defense, National Defence University of Malaysia, Kuala Lumpur, 57000, Malaysia ${ }^{3}$ Centre for Defence Foundation Studies, National Defence University of Malaysia, Kuala Lumpur, 57000, Malaysia

${ }^{4}$ Faculty of Defence Science and Technology, National Defence University of Malaysia, Kuala Lumpur, 57000, Malaysia

\begin{abstract}
The search for new compounds other than oxime as potential reactivator that is effective upon organophosphate poisoning treatments is desired. The less efficacy of oxime treatment has been the core factor. Fourteen compounds have been screened via in silico approach for their potential as sarin-inhibited human acetylcholinesterase poisoning antidotes. The selection of the compounds to be synthesized based on this computational screening, reduces the time and cost needed. To

ARTICLE INFO

Article history:

Received: 18 December 2020

Accepted: 24 February 2021

Published: 19 July 2021

DOI: https://doi.org/10.47836/pjst.29.3.19

E-mail addresses:

raudamohamed@gmail.com (Rauda A. Mohamed) ongkhim@upnm.edu.my (Keat Khim Ong) norhana@upnm.edu.my (Norhana Abdul Halim) azilah@upnm.edu.my (Noor Azilah Mohd Kasim) aminah@upnm.edu.my (Siti Aminah Mohd Noor) victor.feizal@upnm.edu.my (Victor Feizal Knight) rabbani_muhamad@yahoo.com (Rabbani Muhamad) wanmdzin@upnm.edu.my (Wan Md Zin Wan Yunus) *Corresponding author perform the docking study of sarin-inhibited acetylcholinesterase and reactivatorsarin inhibited acetylcholinesterase complexations, a bioinformatics tool was used. Estimation of the nucleophilic attack distance and binding energy of fourteen potential compounds with sarin inhibited acetylcholinesterase complexes to determine their antidote capacities was carried out using Autodock. A commercially available antidote, 2-PAM was used for the comparison. The best docked-pose was further examined with molecular dynamics
\end{abstract}


Rauda A. Mohamed, Keat Khim Ong, Norhana Abdul Halim, Noor Azilah Mohd Kasim, Siti Aminah Mohd Noor,

Victor Feizal Knight, Rabbani Muhamad and Wan Md Zin Wan Yunus

simulation. Apart from being lipophilic, a compound with a carboxylic acid, $(R)$-Bocnipecotic acid is shown to exhibit $6.29 \mathrm{kcal} / \mathrm{mol}$ binding energy with $8.778 \AA$ distance of nucleophilic attack. The stability and flexibility of the sarin-inhibited acetylcholinesterase, complexed with $(R)$-Boc-nipecotic acid suggests this compound should be tested experimentally as a new, promising antidote for sarin-inhibited acetylcholinesterase poisoning.

Keywords: Antidote, docking, in silico, inhibition, organophosphate, oxime, reactivator, simulation

\section{INTRODUCTION}

Acetylcholinesterase (AChE) is a serine hydrolase which hydrolyzes acetylcholine. Acetylcholine exhibits neurotransmitter functions to transfer signals from the nerve to the muscle cell. It is located at the synaptic cleft and the hydrolysis products of this reaction are choline and acetic acid. The accumulation of acetylcholine causes continuity of signaling and leads to neurotoxicity, which results in muscle paralysis, seizures and finally, death. Organophosphorus (OP) is one of the inhibitors that inhibit the hydrolysis of acetylcholine from occurring, thus resulting in the accumulation of acetylcholine. OP poisonings usually happen either from dietary, household erroneous handling, accidental or/and occupational exposure and these incidents are increasing (Baker, 1990). Apart from that, the use of OP as chemical weapons is also alarming, such as the assassination of Kim Jong-Nam in Malaysian airport.

The binding site of AChE acts as a charge relay system and consists of three distinct residues which are Ser203, Glu334 and His447. AChE comprises two dissimilar pockets in the binding site domain which are esteric site and anionic site. Fourteen conserved aromatic amino acids are lined along with these domains (Ranjan et al., 2015). An OP toxicity effect on the central nervous system is initiated through the non-reversible phosphorylation of esterase when it interacts with Ser203 in the AChE molecule. Ser203 together with Trp86 are the critical residues in inactivation and act to guard the inhibitor on the bottleneck of the binding gorge (Patil et al., 2018). OP is substrate analogue to acetylcholine and hence, a similar route is used to enter the active site of $\mathrm{AChE}$ and covalently bind to $-\mathrm{OH}$ group of Ser203 for the inhibition mechanism. The hydroxy moiety of Ser203 attacks the phosphoryl group and caused the leaving group of the OP to leave (Namba et al., 1971).

Dephosphorylation of AChE can be carried out by a highly nucleophilic atom. The mechanism of action is based on the nucleophilic attack of the nucleophile towards the phosphorus atom of the phosphorylated organophosphate-AChE (Figure 1) (Matos et al, 2011). Among this highly nucleophilic atom, oximes were found in the literature as the best reactivator for OP-AChE poisoning. For years, HI6 and 2-PAM have been the leading 
oximes due to their competency to reactivate OP-inhibited AChE (Ajami \& Rebek, 2013; Mercey et al., 2012a; Kuca et al., 2013). However, there are limitations of these oximes due to their quaternary nitrogen charge, which lead to the inefficiency to penetrate the blood-brain barrier (de Souza et al., 2020; Radic et al., 2013; Radic et al., 2012; Sit et al., 2011; Kovarik et al., 2013; Tang et al., 2013). Subsequently, several attempts have been performed to find potential non-ionic oximes.

There were reported studies on the designation and synthesis of non-ionic oxime reactivators which successfully enhanced brain permeability (Mercey et al., 2012b; de Koning et al., 2011). Unfortunately, most of the compounds were hard to synthesis due to their complex structure especially in large quantities which is crucial for in vivo evaluation. Furthermore, the non-charge oximes reduce the reactivity function of the oxime and muddling in the design process of effective oxime-based reactivators. Hence, the finding of a new antidote should be expanding towards the non-oxime group. Katz et al. (2015) has discovered compounds from large bioactive libraries and approved drugs as a potential antidote as tested by in vitro screening. None of these reported potential compounds possessed the oxime structural motive. Bhattacharjee et al. (2015) claimed that the active compounds possess a slight structural resemblance, while Katz et al. (2018) reported the screening compounds to have common structural features such as basic moieties (pyridine, imidazole and piperazine) or Mannich phenol (i.e., phenols representing a benzylic amine in the $\alpha$-position). Specifically, 4-Amino-2((diethylamino)methyl)phenol (ADOC) shows promising potential to reactivate paraoxon-ethyl (PXE) and DIFP-inhibited AChE (Katz et al., 2018).

Our study aims to screen the interaction of charged and uncharged nitrogen from a different group of compounds towards sarin-inhibited AChE. This present study also utilized MD simulation (MDS) to reveal the interactions of the different subdomains of the AChE's active site towards the compound. These compounds have never been investigated as potential reactivators.

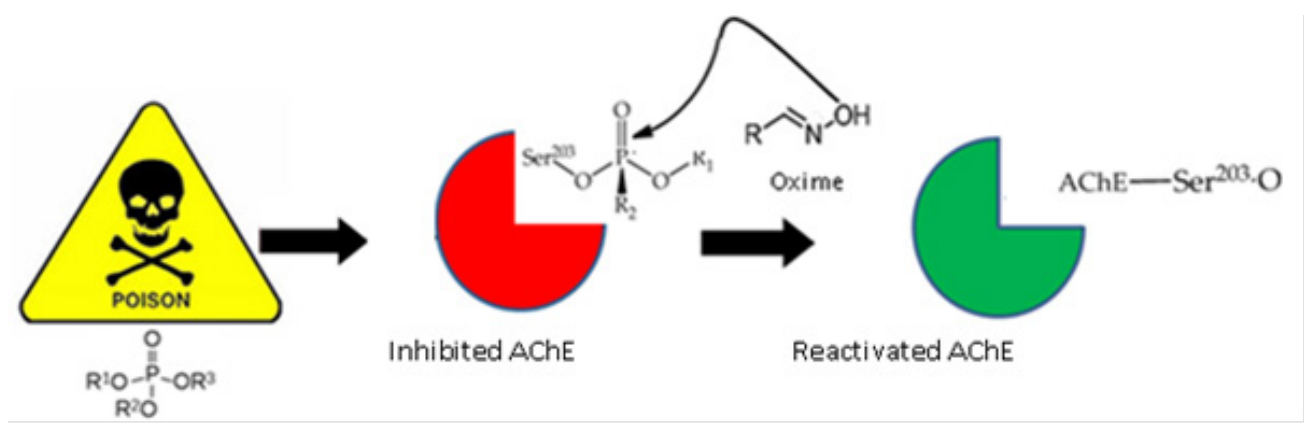

Figure 1. Reactivation mechanism of oxime towards OP inhibited-AChE 
Rauda A. Mohamed, Keat Khim Ong, Norhana Abdul Halim, Noor Azilah Mohd Kasim, Siti Aminah Mohd Noor, Victor Feizal Knight, Rabbani Muhamad and Wan Md Zin Wan Yunus

\section{MATERIALS AND METHODS}

A 3D model structure of human $\mathrm{AChE}$ ( $h \mathrm{AChE}$ ) in apo form and a complex structure of sarin-inhibited $h \mathrm{AChE}$ were downloaded from the RCSB-Protein Data Bank under the code 4EY4 and 5FPQ respectively. The X-ray diffractions of the 3D structure for both proteins have a resolution of around 2.16-2.40 $\AA$. Structural files of sarin and reactivators were obtained from the PubChem library (https://pubchem.ncbi.nlm.nih.gov/) (Kim et al., 2016). The docking process was carried out by AutoDock 4.2.5.1 (Morris et al., 1998) tool with some modification on the commands to suits covalent bonding. Both docking and MD simulation were performed and analyzed using YASARA software version 12.5.7 (YASARA Biosciences GmbH, Austria) (Krieger et al., 2002).

\section{Docking Studies}

Validation of the Autodock 4.2.5.1 Tool to Perform Covalent Docking. The preparation of apo-formed $h \mathrm{AChE}$ (4EY4) structure prior to docking involved the removal of chain $\mathrm{B}$, crystal associated heteroatoms and water molecules. To perform covalent docking, serine-sarin adduct has to be flexible by editing the command on dockrun_mcr (flexres: Ser 203). This is followed by energy minimization for both the receptor and ligand. The entire residue Ser 203 and ligand were selected before the files were separately saved as a .yob file by clicking 'Edit > Select'. The other parameters (the simulation cell was placed around the active sites to target docking at the most important region and the $\mathrm{pH}$ dependent bond orders and hydrogen atoms) were automatically set. Docking analysis using Autodock was performed (Kryger et al., 2000). Both the complex docked-structure of sarin-inhibited $h \mathrm{AChE}$ and the deposited crystal structure of sarin-inhibited $h \mathrm{AChE}$ (5FPQ) were superposed using MUSTANG algorithm (Konagurthu et al., 2006) alignment to validate the docking protocol. In order to further compare the interactions of the dockedsarin $\mathrm{AChE}$ with the literature from the crystal structure of sarin-inhibited $h \mathrm{AChE}$, important intramolecular interactions were highlighted as well.

Docking of Reactivators towards Sarin-inhibited $\boldsymbol{h A C h E}$. The 3D deposited crystal structure of sarin-inhibited $h \mathrm{AChE}$ was further modified by removing crystal associated heteroatoms and water molecules. As mention previously, in order to perform covalent docking, serine-sarin adduct has to be flexible by editing the command on dockrun_mcr (flexres: SGB 203). This is followed by energy minimization for both the receptor and ligand. The entire residue Ser 203 and ligand were selected before the files were separately saved as a .yob file by clicking 'Edit > Select'. Docking analysis using Autodock was performed for the $h \mathrm{AChE}$ complex structure with these selected compounds: salicylamidoxime, hydroxybenzohydrazide, 6-hydroxypicolinohydrazide, pyridine-2-carbohydrazide, picolinohydroxamic acid, 3-pyridinecarbohydroxamic acid, 2-acetylpyridine, pyrimidine, 
acetic acid, salicylic acid, pidolic acid, boc-nipecotic acid and indole butyric acid with 2-PAM as a commercial antidote to screen for the potential reactivators. The structure of sarin and the screened compounds (Figure 2), which have been retrieved from (https:// pubchem.ncbi.nlm.nih.gov/) represent various functional groups with cationic or uncharged properties such as oxime, hydrazide, pyridine, pyrimidine, carboxylic acid and hydroxamic acid.

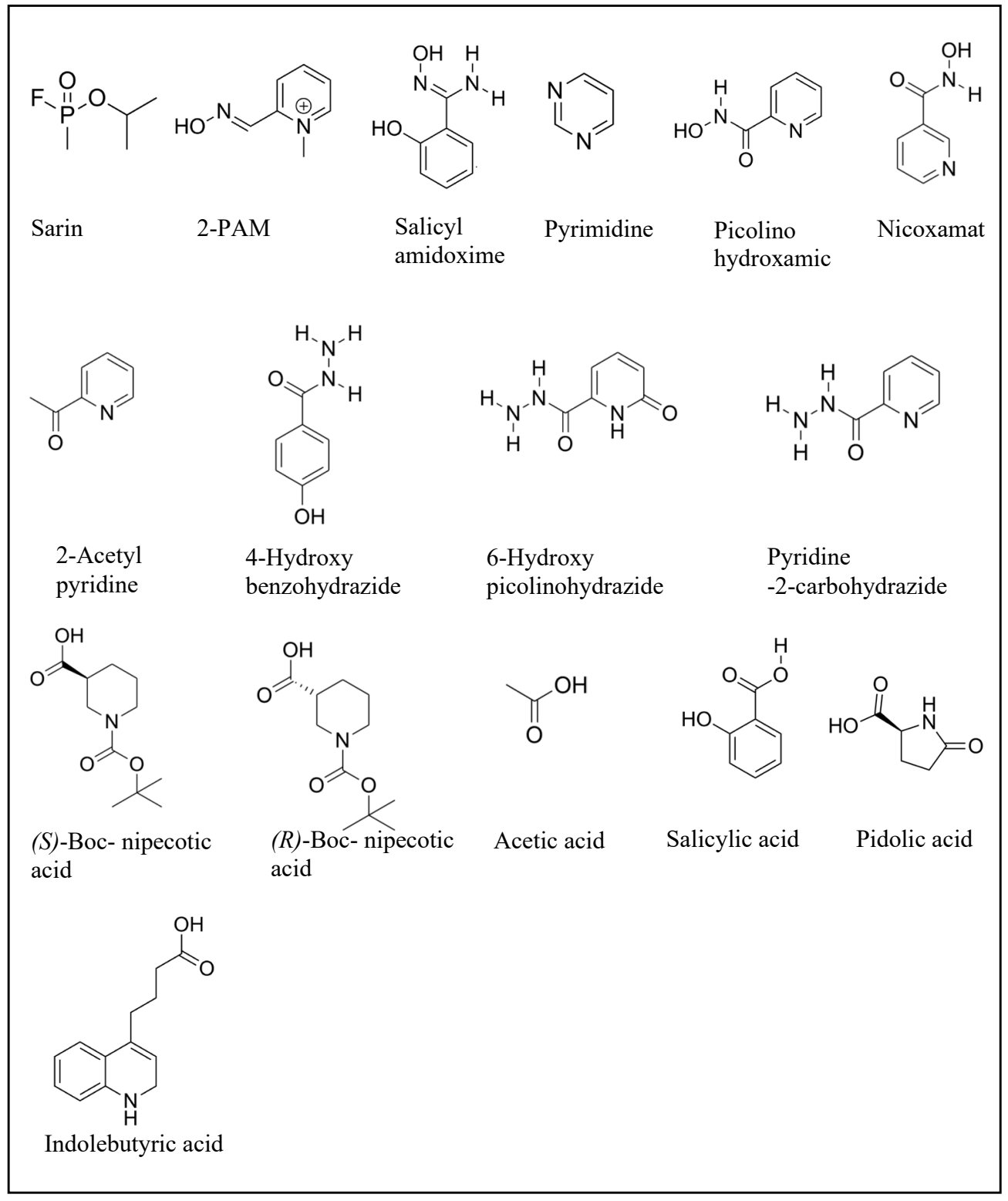

Figure 2. The structures of sarin and the screened compounds for sarin-inhibited $h \mathrm{AChE}$ reactivation 
The binding energy of the sarin-inhibited $h \mathrm{AChE}$ complex with the compounds was estimated and compared. The binding energy is obtained by calculating the energy at the infinite distance between the selected object and the rest of the simulation system (the unbound state) and subtracting the energy of the simulation system (the bound state) (Chen et al., 2015). The reactivators, which have higher binding energy with the sarin-inhibited $h \mathrm{AChE}$ complex, were selected as potential antidotes. In some other docking programs, binding energy with negative value represents better binding, for example, AutoDock. This is because these programs do not report 'binding energies' but the energy required to disassemble a compound into separate components which usually positive.

\section{$\log P$ Calculation to Predict the Selected Compounds Lipophilicity}

For compounds with good binding and reactivation potential (based on their nucleophilic attack distance), $\log P$ determination was carried out using Molinspiration (http://www. molinspiration.com/cgi-bin/properties) to determine their lipophilicity.

\section{Molecular Dynamics Simulation (MDS)}

Simulation of molecular dynamics was performed for the sarin-inhibited $h \mathrm{AChE}$ and sarin-inhibited $h \mathrm{AChE}$ complex with the selected potential reactivator. The pose with high energy value and shorter distances O-P was selected. The simulation protocol started with the covalent geometry corrected and the unwanted water molecules were removed. Optimization of the hydrogen-bond network, and thereafter a cubic simulation cell was created in the periodic boundary state, where the protein of each complex was parameterized by the force field of AMBER03 (Duan et al., 2003). The pH of the system was maintained at 7.4 to mimic the physiological conditions. MDS has been performed for $20 \mathrm{~ns}$ and the resulting trajectories were studied for different analyses. This final system setup was used for the production run and simulation snapshot coordinates were saved every $30 \mathrm{ps.}$

\section{Analysis of MDS Trajectories}

The analyses of the trajectories were performed from replicates of three different simulations run at different initial velocities. All the MDS results were characterized using a preinstalled macro within the YASARA suite including total energy, Root Mean Square Deviation (RMSD), Root Mean Square Fluctuations (RMSF) and Solvent Accessible Surface Area (SASA). RMSD value is the average distance between the atoms estimation during simulation, which suggests structural changes (Ishak et al., 2017). The local variations as well as the residue movement differences could be computed by the RMSF. Both RMSD and RMSF calculate the stability and flexibility of a residue in the enzyme-complex at a given simulated time. Besides, the quality of the complex structure could also determine by the RMSD value (Bagaria et al., 2012). SASA represents the accessibility surface area 
of a biomolecule towards solvent. All visual structure analysis and figure design were performed using YASARA and POVRay (http://www.povray.org) (Krieger \& Vriend, 2014).

\section{RESULTS AND DISCUSSION}

\section{Validation of the Autodock 4.2.5.1 Tool to Perform Covalent Docking}

The molecular surface of sarin-docked $h \mathrm{AChE}$ is shown in Figure 3. Superposition of sarindocked- $h \mathrm{AChE}$ with the deposited crystal structure of sarin-inhibited $h \mathrm{AChE}$ (Figure 4) presented $0.3 \AA$ RMSD value is with $99.81 \%$ sequence identity. The residues of the active sites were fully conserved. These two structures show low variation positions to validate the docking protocol used since the RMSD value falls in the acceptable range of below $1 \AA$. This validation is important to support the reliability of the output for reactivators docked-inhibited AChE study. Several important interactions of the docked-sarin AChE were in agreement with the reported literature on the crystal structure of sarin-inhibited $h \mathrm{AChE}$. Thus, these important intramolecular interactions were highlighted in detail as well.

When the sarin molecule enters into the active sites gorge of the AChE, the sarininhibited $h \mathrm{AChE}$ complex is formed. The aromatic hydrophobic residues lining along the gorge, as shown by Asp74, helps to orient the sarin molecule into the active sites in a

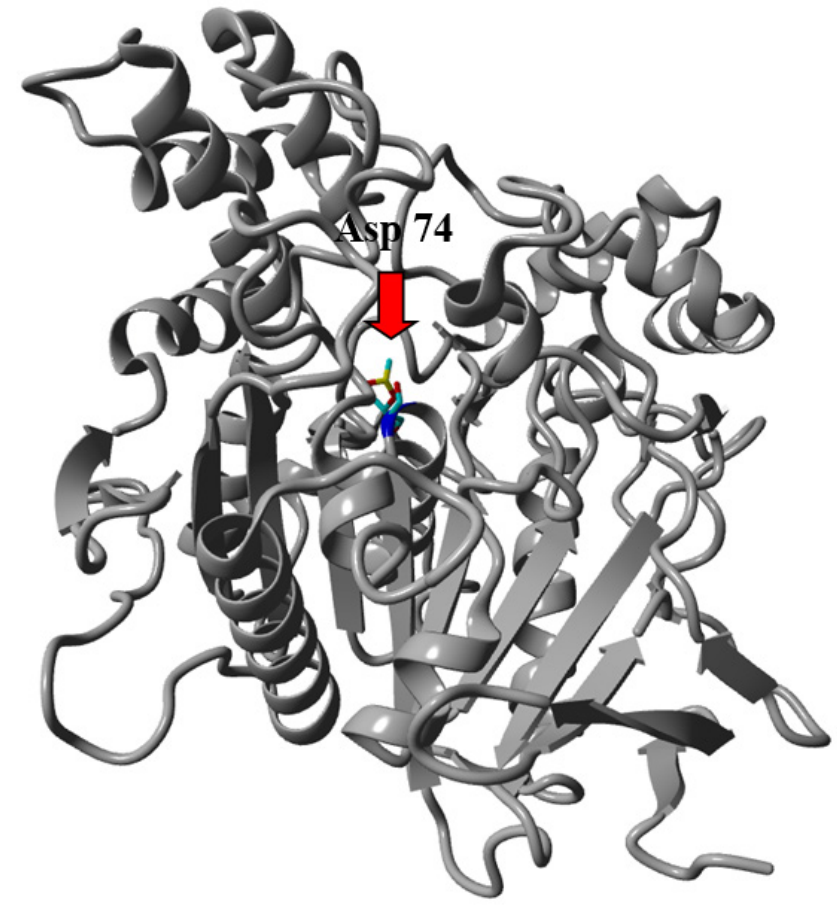

Figure 3. Molecular surface of sarin-docked inhibited $h \mathrm{AChE}$. The red arrow shows the gorge entrance of the binding pocket. Sarin (multicolor) is attracted to the binding pocket by the interaction of polar hydrophobic residues around the gorge entrance 
reactive position (Wlodek et al., 2000). $h$ AChE residue in the catalytic triad, Ser203, will attack the phosphoryl group from sarin. This nucleophilic attack involves the oxygen atom of Ser203 (Qiao et al., 2014). The bond between phosphorus and fluorine becomes weaker as the partial bond forms between the oxygen in serine and the phosphorus in sarin. This molecular configuration is known as a pentacoordinate intermediate. Fluorine acts as a leaving group once the bond between the serine and sarin is fully formed. The ability of the AChE to hydrolyze acetylcholine is entirely disabled because of the stability of the sarin adduct. Table 1 presents the distance, interaction and binding energy of sarin-inhibited AChE. These output values are given by the YASARA integrated Autodock scoring function. The binding energy of sarin towards $h \mathrm{AChE}$ with stated contacting residues was calculated as $3.63 \mathrm{kcal} / \mathrm{mol}$.

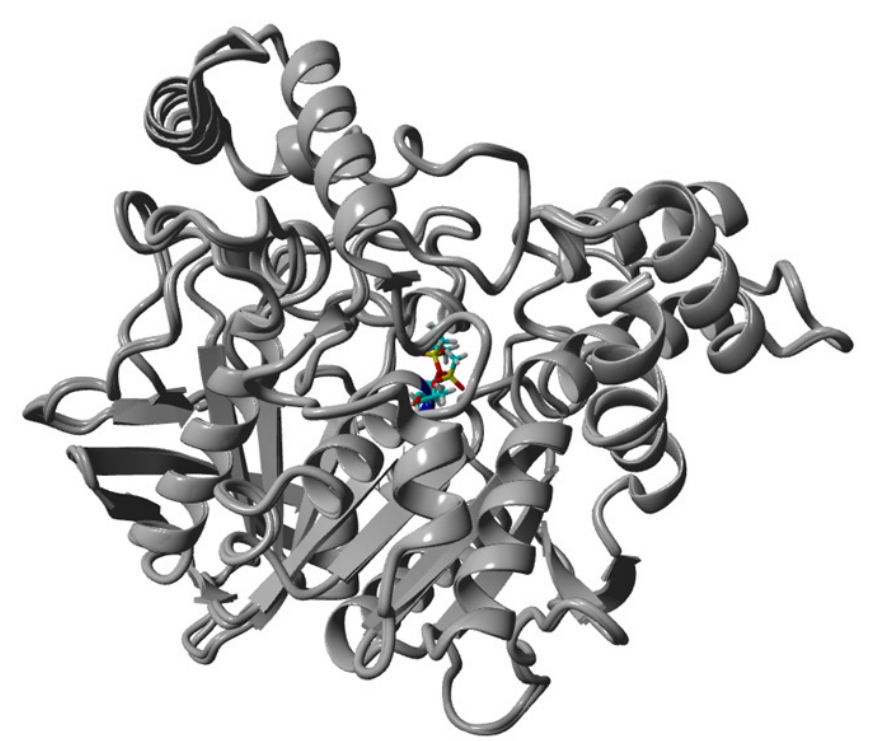

(a)

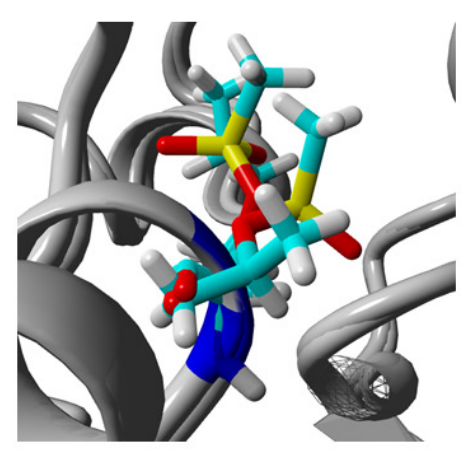

(b)

Figure 4. (a) Superposition of sarin-inhibited $h \mathrm{AChE}$ with the deposited crystal structure of sarin-inhibited $h \mathrm{AChE},(b)$ a zoomed-in figure of the superposition, multicolor denotes sarin

Sarin is categorized as a classical nerve agent in which its structure, bearing a dimethoxy or diethoxy group attached to a phosphorylated $\mathrm{AChE}$ consequence in a complex that can be easily reactivated (Lotti, 2010). This fact supports the low binding energy value of sarin towards $h$ AChE. Ser203, Gly121 and Gly122 are the AChE residues that create a hydrogen bond towards sarin with a distance of approximately 1.03-2.04 $\AA$. Residues involved in the sarin-inhibited $h \mathrm{AChE}$ complex are shown in Figure 5. Gly121 and 122 form hydrogen bonds with the oxygen from the sarin molecule (shown by the yellow dotted line). Ser203, 
Table 1

Distance, interaction and binding energy of sarin-inhibited $h A C h E$

\begin{tabular}{lccc}
\hline $\begin{array}{l}\text { Distance } \\
\text { O-P } \\
(\AA)\end{array}$ & $\begin{array}{c}\text { H-bond } \\
\text { interactions }\end{array}$ & $\begin{array}{c}\text { Binding } \\
\text { energy } \\
(\mathrm{kcal} / \mathrm{mol})\end{array}$ & Peripheral site interactions \\
\hline 0.98 & Ser203, & 3.63 & $\begin{array}{c}\text { Gly122, Glu202, Ser203, Ala204, Gly205, } \\
\text { Ala206, Ala207, Gln228, Ser229, Gly230, } \\
\text { Gly121, }\end{array}$ \\
Gly122 & & $\begin{array}{c}\text { Ala231, Trp236, Phe295, Phe297, Phe338, } \\
\text { Val407, His447. }\end{array}$ \\
\hline
\end{tabular}

Glu334 and His447 are the active site's residues for the catalytic machinery of $h$ AChE. The nucleophilic oxygen from Ser203 attacks the phosphoryl group of sarin, forming the bonding with a distance of $3.206 \AA$, which is a new forming bond between Ser203 and sarin. Trp86 interacts with sarin for the maximum $\pi$-cation interaction on the anionic subsite of the AChE apart from Ser203 (Patil et al., 2018). This residue is also reported to guard the inhibitor at the bottleneck on the binding gorge. The role of Trp86, Tyr124 and Ser203 is to hold sarin in its binding cavity (Zhang et al., 2016; Abou-Donia et al., 2016). Intramolecular $\pi-\pi$ interaction of Phe297 with other $h \mathrm{AChE}$ residues is also detected, whereby this interaction is significant in terms of most of the OP-AChE interaction. The sarin AChE complex is stabilized by hydrophobic interactions.

\section{Docking Study of the Selected Compounds towards Sarin-inhibited $\boldsymbol{h A C h E}$}

The AChE has two important sites for the reactivation to occur, known as the PAS and the esteric site. These residues, Trp86, Tyr124, Phe297, Tyr337 and Tyr341, are the major contributors for the hydrophobic interaction and ligand stabilization in the peripheral site area (de Almeida et al., 2016). Table 2 presents the distance, interaction and binding energy of the reactivators towards sarin-inhibited AChE compared to commercially available 2-PAM. These values were calculated by the YASARA integrated Autodock scoring function. Larger molecules give higher binding energy despite their compound charge, which highly due to the H-bonds formed with the amino acids and their interaction energies (Schaeffer, 2008). (R)-Boc-nipecotic acid is among the compound with a larger structure and exhibits high binding energy $(6.29 \mathrm{kcal} / \mathrm{mol})$ with the shortest nucleophilic $\mathrm{O}-\mathrm{P}$ distance.

The detailed interaction of this compound is further discussed below. Another factor that contributes to the binding energy value, is the charged or uncharged oxime group which affects its affinity for the complex $h \mathrm{AChE} / \mathrm{sarin}$ (Colovic et al., 2013). The binding energy of salicylamidoxime is lower as compared to 2-PAM. This might occurs due to the charged quaternary group of the oxime interacts with the anionic center of AChE (Musilek et al., 2007). For non-oxime reactivator, which has been reported by Cadieux et al. (2016), 


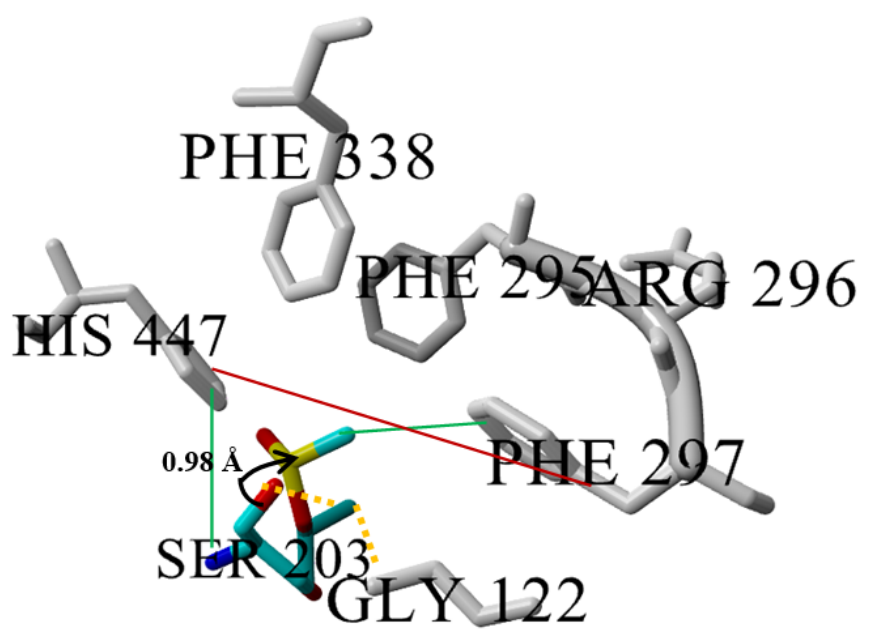

Figure 5. Residues involved in the sarin-inhibited $h \mathrm{AChE}$ complex interactions. Multicolored represents sarin, while gray color denotes $h \mathrm{AChE}$. The arrow represents the nucleophilic attack distance from Ser203 towards the phosphorus atom of sarin, the yellow dotted line represents hydrogen bonding while red and green lines denote $\pi-\pi$ and hydrophobic interactions, respectively

the alkylation or acylation of the amine (aniline) affects binding affinity, whereby the para position of the amine concerning the hydroxyl group is preferred. The presence or position of the hydroxyl group is also crucial for reactivation (Cadieux et al., 2016). Additionally, the existence or position of another amine (benzylic amine) highly influences the binding affinity compared to reactivation. Compounds under the hydrazide group display moderate binding energies with shorter nucleophilic distances except for pyridine-2-carbohydrazide which has a longer distance towards O-P. This is due to the absence of the hydroxyl group (strong nucleophile) in its benzene ring.

Hydroxamic acid group consists of two compounds that only differs at their N position; meta and ortho have a distinct nucleophilic distance with slightly higher binding energy recorded for nicoxamat with ortho position. The substituent position does affecting the reactivation activity due to electron cloud distribution (de Koning et al., 2018; Bregente \& Yunes, 1997). Interestingly, compounds in carboxylic acids show high binding energy especially for $(R)$-Boc-nipecotic acid, $(S)$-Boc-nipecotic acid and indolebutyric acid due to the presence of the amine group in their benzene ring. Both Boc-nipecotic acid have amine and hydroxyl group in the para position which is favored, the binding energy and nucleophilic attack distance values are promising (Cadieux et al., 2016). (R) isomer shows a slightly lower binding energy value compared to the $(S)$ isomer which might due to the further position of this isomer towards the anionic subsite. This subsite is responsible for the binding of the reactivator to steer towards AChE's active site. Nevertheless, the $(R)$ 
Table 2

Distance, interaction and binding energy of the reactivators towards sarin-inhibited hAChE compared to commercially available 2-PAM

\begin{tabular}{|c|c|c|c|c|}
\hline Reactivators & $\begin{array}{c}\text { Distance } \\
\text { O ‥ OP } \\
(\AA)\end{array}$ & $\begin{array}{c}\text { H-bond } \\
\text { interactions }\end{array}$ & $\begin{array}{c}\text { Binding } \\
\text { energy } \\
\text { (kcal/ } \\
\text { mol) }\end{array}$ & $\begin{array}{c}\text { Peripheral } \\
\text { site interactions }\end{array}$ \\
\hline 4-hydroxybenzohydrazide & 4.346 & $\begin{array}{l}\text { Tyr124, } \\
\text { Arg296 }\end{array}$ & 5.93 & $\begin{array}{c}\text { Tyr72, Asp74, } \\
\text { Tyr124, Trp286, } \\
\text { Tyr341 }\end{array}$ \\
\hline 2-acetylpyridine & 9.800 & $\begin{array}{l}\text { Tyr124, } \\
\text { Arg296 }\end{array}$ & 4.21 & $\begin{array}{c}\text { Tyr124, Trp286, } \\
\text { Tyr341 }\end{array}$ \\
\hline Salicylamidoxime & 15.95 & $\begin{array}{l}\text { Tyr124, } \\
\text { Arg296 }\end{array}$ & 5.54 & $\begin{array}{c}\text { Trp86, Gly120 } \\
\text { Gly121, Tyr124, } \\
\text { Ser203, His } 447 \text {, } \\
\text { Gly448 }\end{array}$ \\
\hline 2-PAM & 7.426 & $\begin{array}{l}\text { Tyr124, } \\
\text { Arg296 }\end{array}$ & 6.69 & $\begin{array}{c}\text { Trp86, Gly120, } \\
\text { Gly121, } \\
\text { Ser203 Tyr337, } \\
\text { His447, Gly448 }\end{array}$ \\
\hline Salicylic acid & 8.825 & $\begin{array}{l}\text { Tyr124, } \\
\text { Arg296 }\end{array}$ & 5.13 & $\begin{array}{c}\text { Trp86, Gly120, } \\
\text { Gly121, Ser203, } \\
\text { Tyr337, His447, } \\
\text { Gly448 }\end{array}$ \\
\hline 6-hydroxypicolinohydrazide & 6.868 & $\begin{array}{l}\text { Tyr124, } \\
\text { Arg296 }\end{array}$ & 5.51 & $\begin{array}{l}\text { Trp86, Gly120, } \\
\text { Gly121, Tyr124, } \\
\text { Ser203, Tyr337, } \\
\text { His447, Gly448 }\end{array}$ \\
\hline Acetic acid & 21.133 & - & 3.95 & - \\
\hline (R)Boc-nipecotic acid & 8.778 & $\begin{array}{l}\text { Phe295, } \\
\text { Tyr341 }\end{array}$ & 6.29 & $\begin{array}{c}\text { Tyr124, } \\
\text { SGB203 } \\
\text { Trp286, } \\
\text { Leu289, } \\
\text { Arg296, } \\
\text { Phe297, Tyr337, } \\
\text { Phe338, Tyr341 }\end{array}$ \\
\hline (S)Boc-nipecotic acid & 10.958 & $\begin{array}{l}\text { Tyr124, } \\
\text { Arg296 }\end{array}$ & 6.91 & $\begin{array}{c}\text { Tyr72, Tyr124, } \\
\text { Trp286, Tyr337, } \\
\text { Tyr341 }\end{array}$ \\
\hline Nicoxamat & 9.748 & $\begin{array}{l}\text { Tyr 124, } \\
\text { Arg296 }\end{array}$ & 5.21 & $\begin{array}{c}\text { Tyr72, Tyr124, } \\
\text { Ser203, Trp286, } \\
\text { Phe338, Tyr341 }\end{array}$ \\
\hline
\end{tabular}


Rauda A. Mohamed, Keat Khim Ong, Norhana Abdul Halim, Noor Azilah Mohd Kasim, Siti Aminah Mohd Noor,

Victor Feizal Knight, Rabbani Muhamad and Wan Md Zin Wan Yunus

Table 2 (Continued)

\begin{tabular}{|c|c|c|c|c|}
\hline Reactivators & 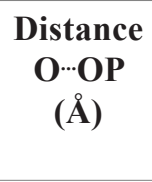 & $\begin{array}{c}\text { H-bond } \\
\text { interactions }\end{array}$ & $\begin{array}{c}\text { Binding } \\
\text { energy } \\
\text { (kcal/ } \\
\text { mol) }\end{array}$ & $\begin{array}{c}\text { Peripheral } \\
\text { site interactions }\end{array}$ \\
\hline Indolebutyric acid & 15.837 & $\begin{array}{l}\text { Tyr124, } \\
\text { Arg296 }\end{array}$ & 5.98 & $\begin{array}{c}\text { Tyr72, Asp74, } \\
\text { Gly121, Gly122, } \\
\text { Tyr124 Ser203, } \\
\text { Trp286, Tyr337, } \\
\text { Phe338, Tyr341 }\end{array}$ \\
\hline Picolinohydroxamic acid & 15.002 & $\begin{array}{l}\text { Tyr124, } \\
\text { Arg296 }\end{array}$ & 4.92 & $\begin{array}{c}\text { Trp86, Gly120, } \\
\text { Gly121, Ser203, } \\
\text { Tyr337, His447, } \\
\text { Gly448 }\end{array}$ \\
\hline Pidolic acid & 9.950 & $\begin{array}{l}\text { Tyr124, } \\
\text { Arg296 }\end{array}$ & 4.51 & $\begin{array}{c}\text { Tyr124, Trp286, } \\
\text { Tyr341 }\end{array}$ \\
\hline Pyridine-2-carbohydrazide & 19.422 & $\begin{array}{l}\text { Tyr124, } \\
\text { Arg296 }\end{array}$ & 4.84 & $\begin{array}{c}\text { Trp86, Gly120, } \\
\text { Gly121, Gly122, } \\
\text { Tyr124, Ser203, } \\
\text { Tyr337, His447, } \\
\text { Gly448 }\end{array}$ \\
\hline Pyrimidine & 9.856 & $\operatorname{Arg} 296$ & 2.58 & Trp286, Tyr341 \\
\hline
\end{tabular}

and $(S)$ configuration of this compound seems to highly affect the nucleophilic distance which shows the nucleophile from $(R)$ position directing towards the OP.

Indolebutyric acid which has a hydroxyl group located far from its benzene ring, shows a longer nucleophilic distance. Salicylic acid shows lower binding energy and shorter nucleophilic distance because of the absence of the $\mathrm{N}$ atom and the presence of the hydroxyl group respectively. Pidolic and acetic acid, which have no benzene ring, recorded low binding energy. Both pyridine and pyrimidine show lower binding energies, although they exhibit an amine group, which might due to the smaller size of the structures. Based on the nucleophilic attack distances of all the tested compounds, 4-hydroxybenzohydrazide, 6-hydroxypicolinohydrazide and $(R)$-Boc-nipecotic acid show higher reactivation potential. Nevertheless, since lipophilicity is another important factor to be considered, $\log P$ values for 4-hydroxybenzohydrazide, 6-hydroxypicolinohydrazide and $(R)$-Boc-nipecotic acid were recorded as $-0.16,-1.19$ and 1.40 respectively. This explains our preference towards $(R)$-Boc-nipecotic acid. Molecular surface view of the docking of $(R)$-Boc-nipecotic acid towards sarin-inhibited $h \mathrm{AChE}$ is shown in Figure 6. Asp74 appears at the gorge entrance which helps to steer the molecule into the active sites in the reactive orientation. Asp74 
which is located at the PAS of human AChE is recorded as the first step in the catalytic pathway and affects the binding energy (Mallender et al., 2000).

Some experimental results highlight this finding, whereby the quaternary nitrogen or the charge oxime is crucial for the affinity towards the OP/AChE complex (Shafferman et al., 1992; Barak et al., 1994; Mallender et al., 2000; Ordentlich et al., 2004; Johnson \& Moore, 2006; Artursson et al., 2009). de Souza et al. (2020) described that based on the binding energies of 2-PAM and HI-6 towards AChE-OP, a higher affinity of HI-6 towards the AChE-OP complex is seen. This highlights the contribution of the two quaternary $\mathrm{N}$ atoms in electrostatic effects which granted twice more affinity compared to 2-PAM. Meanwhile, in this study, binding energies of 2-PAM and ( $R$--Boc-nipecotic acid towards sarin-inhibited $h \mathrm{AChE}$ showed a small difference in their binding energies values since both tested reactivators have only one $\mathrm{N}$ atom in their structure.

In order to reactivate the AChE-OP complex, a reactivator should exhibit good affinity and reactivity. Good affinity derived from these physicochemical features such as; electrostatic effects, hydrophobic interactions and steric compatibility, while reactivity derived from the nucleophilicity of the oxime or non-oxime moiety (de Souza et al., 2020). Hence, the structure and the position of the reactivator also affect the reactivation potential. (R)-Boc-nipecotic acid is seen to interact with PAS residues (Tyr124, Trp286, Phe297, Tyr337 and Tyr341) from the $h \mathrm{AChE}$. These residues are essential in the binding of the reactivators, thus exposing them to the anionic subsite where electrostatic interaction occurs. Figure 7 shows the hydrogen bonding of Phe295 and Tyr341 towards $(R)$-Boc-nipecotic acid. The distance is around 2.08-2.12 A. Nucleophilic attack of the hydroxyl group from (R)-Boc-nipecotic acid towards the sarin-inhibited $h \mathrm{AChE}$ complex occurs with a distance of $8.778 \AA$ (Figure 8).

Hence, the sarin adduct from the oxygen of the active site serine is removed and reactivate the $h \mathrm{AChE}$. The affinity for the whole system increases when the affinity between the reactivators and the P-site area increases, and causes stabilization (de Almeida et al., 2016).

Figure 9 shows the interaction of $\mathrm{OH}$ from Tyr124 at the anionic site with nitrogen from $(R)$-Boc-nipecotic acid with a distance of $3.603 \AA$ (electrostatic interaction). Aromatic rings of Tyr124 flank the indole group of Trp286 and together they interact with charged groups of ligand (Johnson \& Moore, 2006). Moreover, the indole ring of Trp286 can make different interaction modes towards the ligand, such as aromatic-aromatic, stacking and $\pi$-cation depending on the nature of the ligand. Hydrophobic interactions of $h \mathrm{AChE}$ residues towards $(R)$-Boc-nipecotic acid is also detected for complex stabilization. Apart from these interactions, $(R)$-Boc-nipecotic acid might also introduce as a carboxylic acid moiety source, which can be attached to various oximes that have been successfully proven as a potential antidote. A study carried out by de Koning et al. (2017), which reported the 
insertion of various linker lengths of carboxylic acid to the pyridinium and imidazole oximes, has successfully reactivated sarin-inhibited AChE.

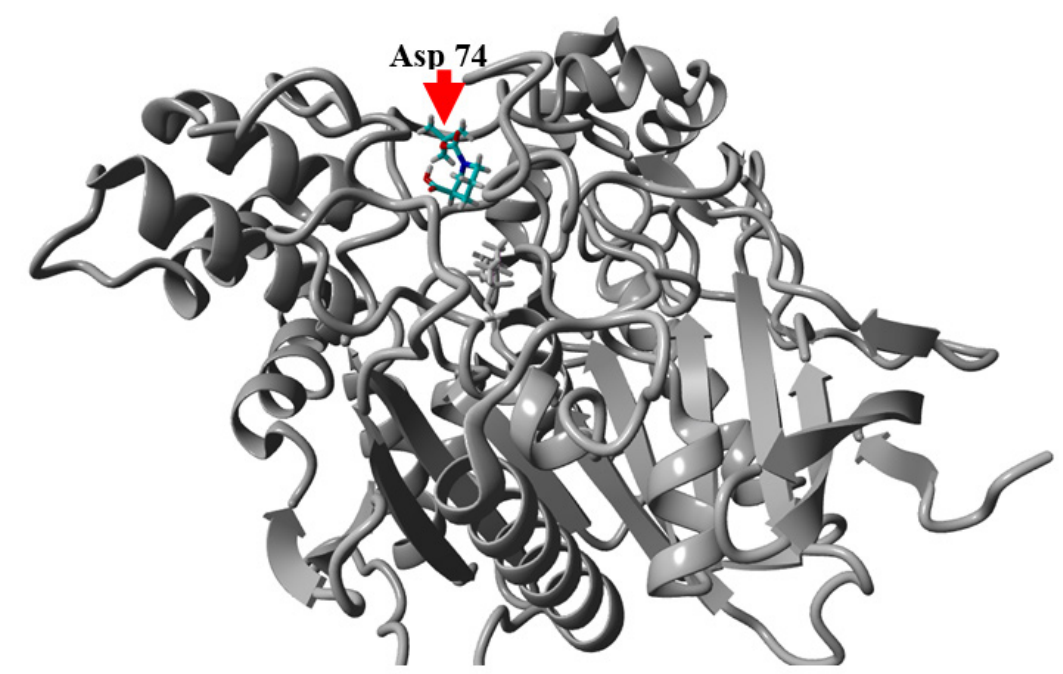

Figure 6. Docking of (R)-Boc-nipecotic acid towards sarin-inhibited $h$ AChE. The red arrow shows the gorge entrance of the binding pocket. Multicolor represents (R)-Boc-nipecotic acid and gray represents inhibited $h \mathrm{AChE}$

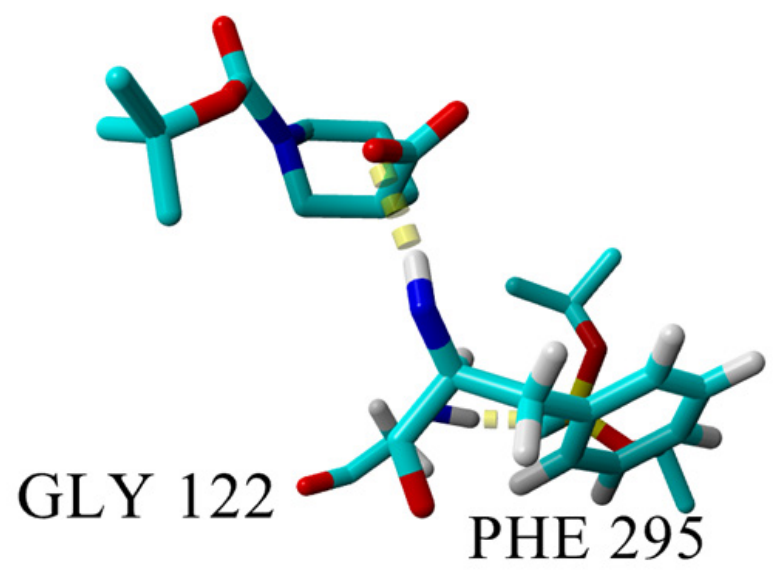

Figure 7. Hydrogen bonding of Phe295 and Tyr341 towards (R)-Boc-nipecotic acid (indicated by the yellow dotted line) 


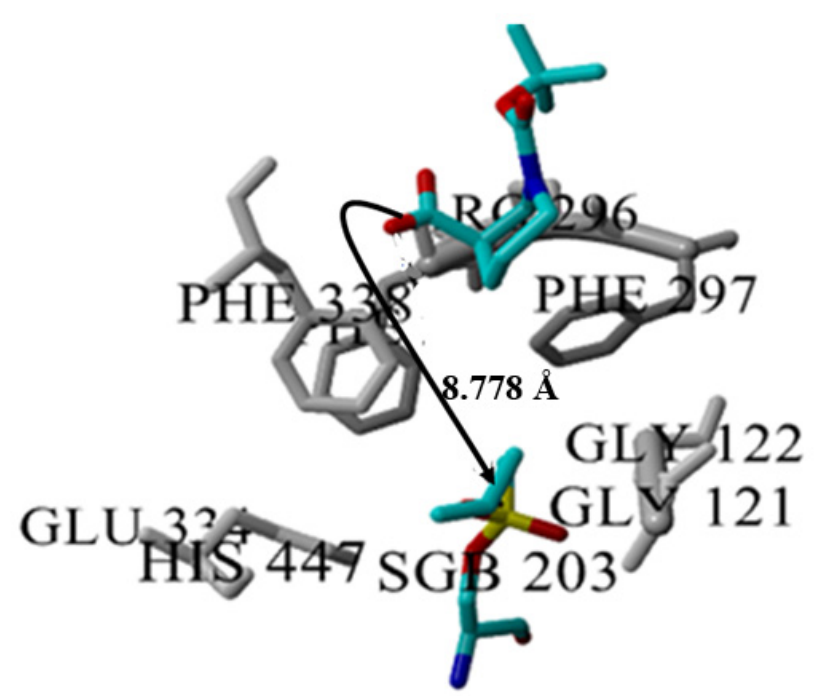

Figure 8. Nucleophilic attack of $\mathrm{OH}$ from (R)-Boc-nipecotic acid towards phosphorus atom (from sarin- Ser203 adduct). The bonding distance is $8.778 \AA$

\section{MDS Analysis of $\boldsymbol{h} \mathrm{AChE}-s a r i n$ and $\boldsymbol{h} \mathrm{AChE}-\operatorname{sarin} /(\boldsymbol{R})$-Boc-nipecotic Acid}

The best pose for $h \mathrm{AChE}$-sarin/(R)-Boc-nipecotic acid complex was further investigated by MDS. The energy plot for the complex $h$ AChE-sarin with and without reactivator $(R)$ Boc-nipecotic acid during $20 \mathrm{~ns}$ of MDS is presented in Figure 10. The results indicated that both $h \mathrm{AChE}$-sarin and $h \mathrm{AChE}$-sarin/(R)-Boc-nipecotic acid docking complexes showed initial energy around $-1.390000 \times 10^{6} \mathrm{~kJ} / \mathrm{mol}$, fluctuated up to $1.35 \mathrm{~ns}$ and afterward the complex $h \mathrm{AChE}$-sarin/(R)-Boc-nipecotic acid stabilized at an energy range of -1.376385 $\mathrm{x} 10^{6} \mathrm{~kJ} / \mathrm{mol}$. This energy level is slightly higher compared to the energy level of $h \mathrm{AChE}-$ sarin complex before docking with $(R)$-Boc-nipecotic acid, which stabilized at an energy range of $-1.381719 \times 10^{6} \mathrm{~kJ} / \mathrm{mol}$. The lower the energy, the higher the stability (Yellapu et al., 2015). The small increment in the energy levels of the $h \mathrm{AChE}-$ sarin/(R)-Boc-nipecotic acid indicates the stability of this complex after reactivation occurs.

RMSD plot for the complexes $h$ AChE- sarin with and without $(R)$-Boc-nipecotic acid during 20 ns of MDS is presented (Figure 11) to analyze the stability and affinity of the system. There is a slight variation in the RMSD value of $h$ AChE-sarin complex before and after docking with $(R)$-Boc-nipecotic acid. Even though the RMSD fluctuated at the initial stage, after $1.35 \mathrm{~ns}$, the $h \mathrm{AChE}-\mathrm{sarin} /(R)$-Boc-nipecotic acid complex stabilized within the same RMSD range as that of $h \mathrm{AChE}$-sarin complex at a value below $2.00 \AA$. It is therefore appears from the MDS, that complex $h \mathrm{AChE}$-sarin/(R)-Boc-nipecotic acid is stable, thus indicating the selective reactivating mode of $(R)$-Boc-nipecotic acid against $h \mathrm{AChE}$-sarin. 


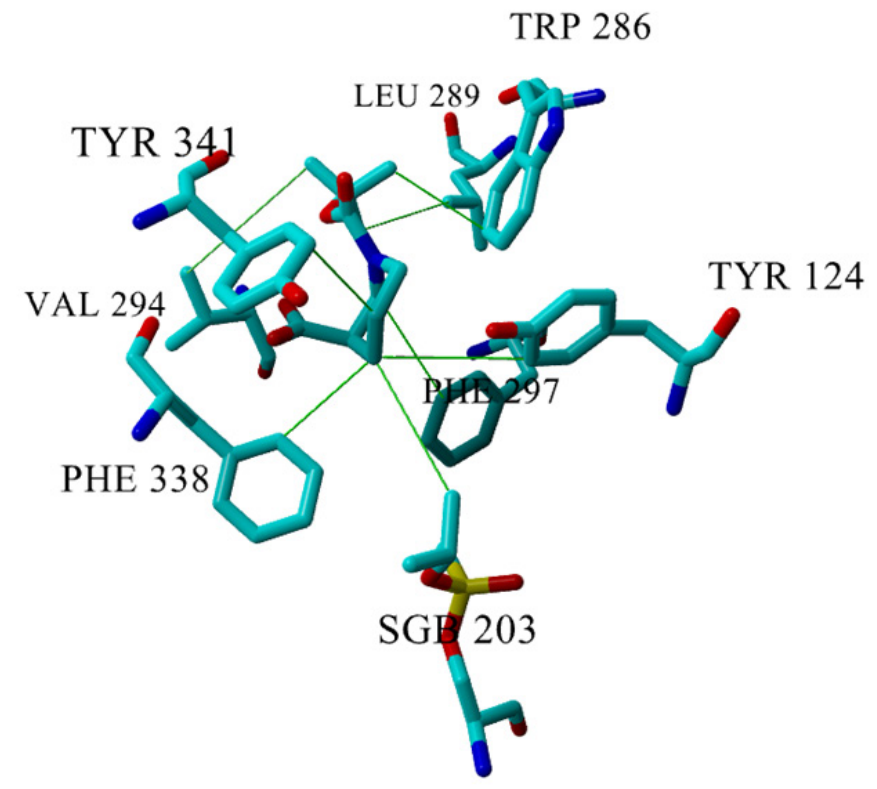

Figure 9. The interactions of $\mathrm{OH}$ from Tyr124 at the anionic site with nitrogen from $(R)$-Boc-nipecotic acid (multicolor) with a distance of $3.603 \AA$ (electrostatic interaction). Hydrophobic interactions of contacting residues towards $(R)$-Boc-nipecotic acid (indicated by the green line)

This is also consistent with the variable docking scores. The RMSD value for $h$ AChEsarin/(R)-Boc-nipecotic acid complex has deviated from sarin-inhibited $h \mathrm{AChE}$ complex at around $0.236 \AA$ which represents low position variation. The digression could be related to the affinity and the interactions performed with the enzymes, which also presented by the higher binding energy of $h \mathrm{AChE}$-sarin/(R)-Boc-nipecotic acid complex as compared to the $h \mathrm{AChE}$-sarin. $h \mathrm{AChE}$-sarin/(R)-Boc-nipecotic acid complex exhibits larger position variation at the early stage of the simulation. However, at the later stage of the simulation, the values were restricted to the range of $1.612 \AA$ and $1.739 \AA$, which can be regarded as stable, given its degree of freedom and frame size. This behavior can be described by the larger volume of the interaction site of $(R)$-Boc-nipecotic acid inside the complex AChEsarin. For a better understanding of the structural variations and the conformation flexibility of both complexes, RMSFs of $\mathrm{C} \alpha$ on the protein backbone were assessed to analyze the variations of every $\mathrm{AChE}$ amino acid residue towards the simulation time.

According to Baweja et al. (2017) and Ishak et al. (2017), residues within protein structures show low RMSF values, while loop regions and residues located on the protein surface show higher RMSF values. Some high peaks were detected around amino acid residues 72-98, 250-280 and 330-360 for structure $h$ AChE-sarin complex compared to $h \mathrm{AChE}-\mathrm{sarin} /(R)$-Boc-nipecotic acid structure, which shows no peak. This can be seen 


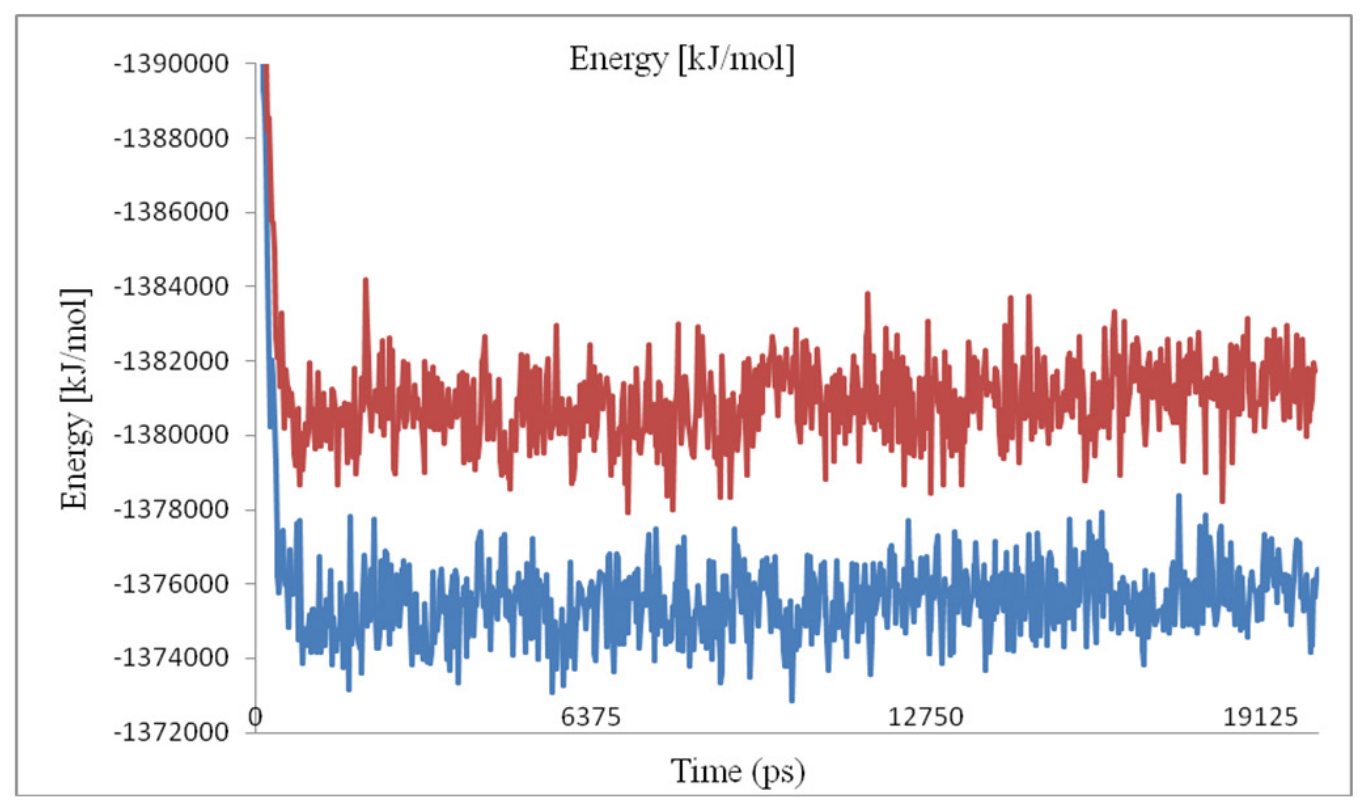

Figure 10. Energy plot for the complex $h \mathrm{AChE}$-sarin without (red) and with (R)-Boc-nipecotic acid (blue) during $20 \mathrm{~ns}$ of MDS

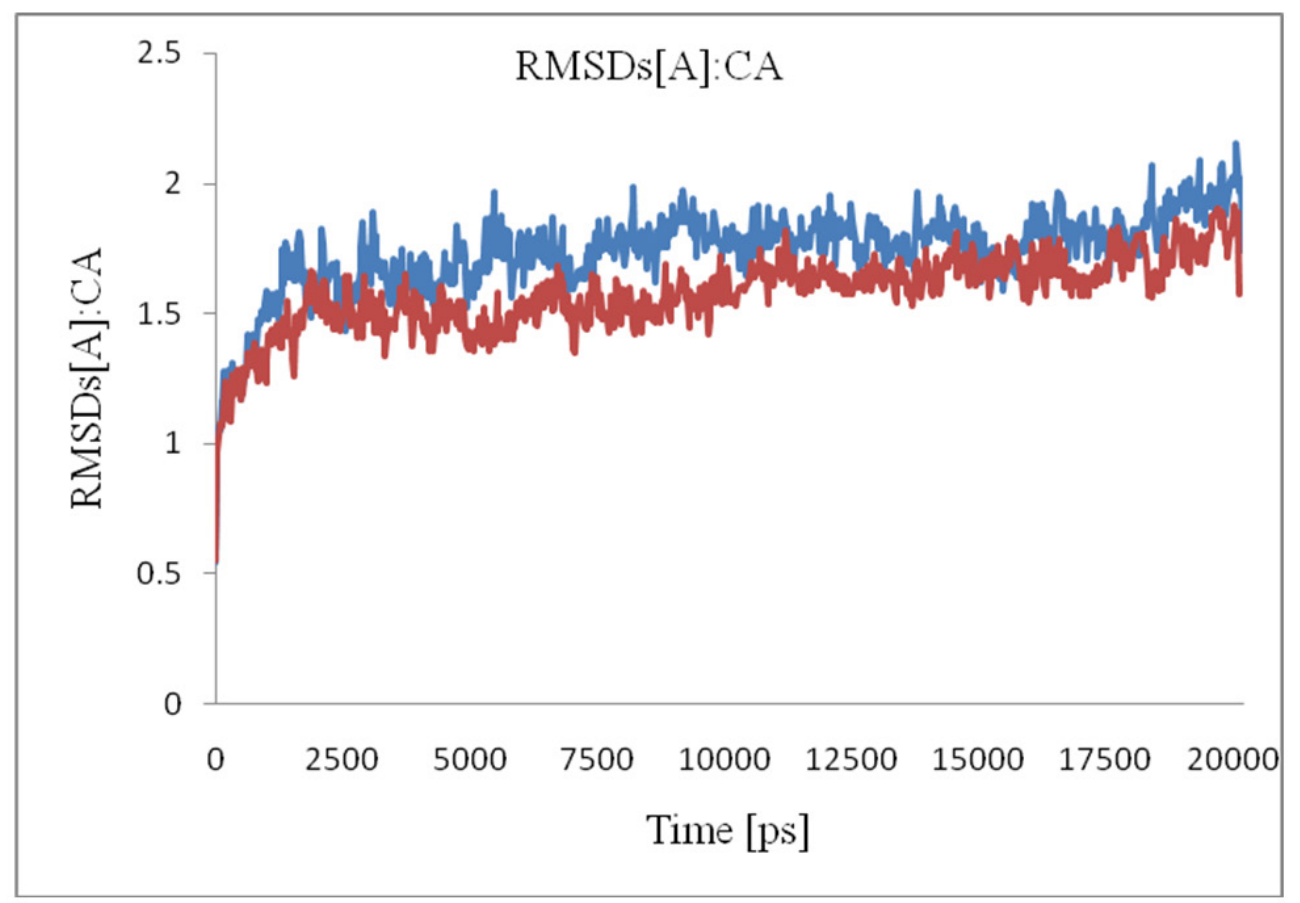

Figure 11. RMSD plot for the complexes $h$ AChE-sarin without (red) and with (R)-Boc-nipecotic acid (blue) during $20 \mathrm{~ns}$ of MDS 


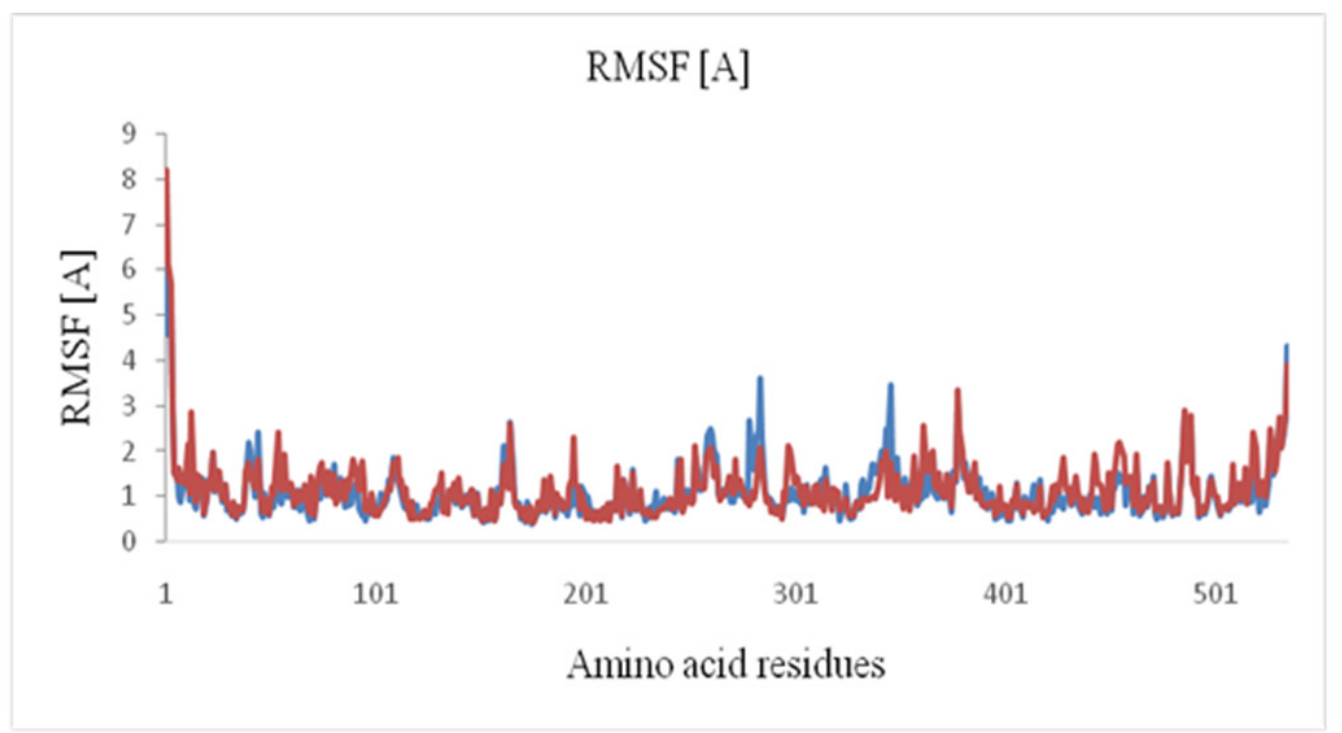

Figure 12. RMSF plot for the complexes $h$ AChE-sarin without (blue) and with (R)-Boc-nipecotic acid (red) during 20 ns of mds

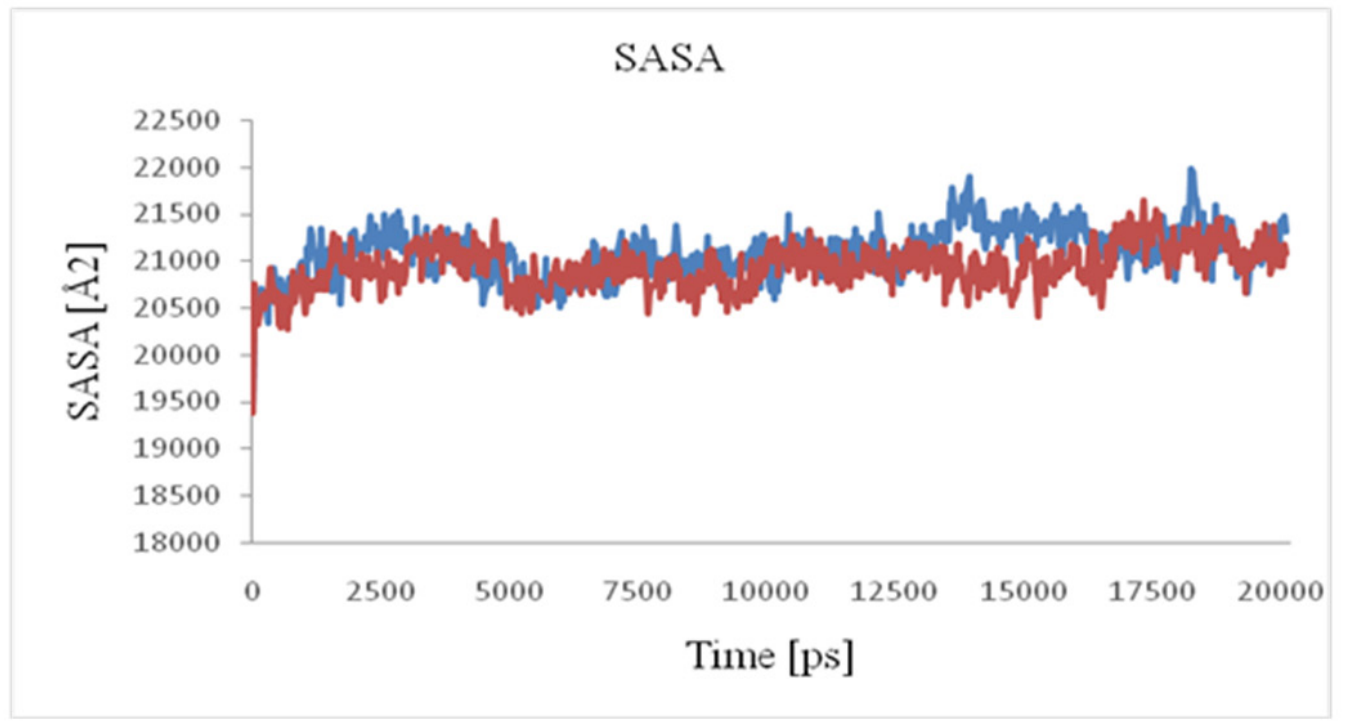

Figure 13. SASA plots for the complexes $h$ AChE-sarin without (blue) and with $(R)$-Boc-nipecotic (red) acid during 20 ns of MDS 
from the RMSF plot for the complexes $h \mathrm{AChE}$-sarin with and without reactivator $(R)$ Boc-nipecotic acid during 20 ns of MDS (Figure 12). Since the interacting PAS residues responsible for the reactivation mechanism are located within these residues, it strengthens the possible interaction occurred between $(R)$-Boc-nipecotic acid with these residues. Ser203 shows no peak for the $h \mathrm{AChE}$-sarin complex since this residue is responsible for the nucleophilic attack.

Previously, literature that reported on the MDS of sarin-AChE complex, shows that sarin-AChE presents greater position variation from the starting system configuration (de Souza et al., 2020). Sarin can affect the whole protein structure due to its interaction with the AChE active site's. This led to a greater volume of the interaction site, directly affecting the interactions between amino acids and oximes. Referring to SASA plots for the complexes $h \mathrm{AChE}$-sarin with and without reactivator $(R)$-Boc-nipecotic acid during $20 \mathrm{~ns}$ of MDS (Figure 13), SASA values of both $h \mathrm{AChE}$-sarin and $h \mathrm{AChE}$-sarin/(R)-Bocnipecotic acid complexes fluctuate at a range of 19500-21000 $\AA^{2}$ until 1.35 ns. Following that, both complexes show a similar SASA pattern of up to $12.5 \mathrm{~ns}$. However, after that, the pattern slightly changes for $h \mathrm{AChE}$-sarin whereby its SASA value increased compared to $h \mathrm{AChE}-\mathrm{sarin} /(R)$-Boc-nipecotic acid complex. This might represent the beginning point of the reactivation process. Higher scores mean that more molecules are sticking out into the water. Lower scores mean that more molecules are buried in the protein (Mukherjee \& Bahadur, 2018).

Hence, it shows that the increment of the SASA value for $h$ AChE-sarin complex is due to no interaction or reactivation occurring. After the reactivation, the protein accessible surface area is smaller since the protein became compact due to the $\mathrm{H}$ bond between $(R)$ Boc-nipecotic acid and $h \mathrm{AChE}$-sarin complex thus explained the lower SASA value of $h \mathrm{AChE}-\mathrm{sarin} /(R)$-Boc-nipecotic acid complex after $12.5 \mathrm{~ns}$. As described in the docking part previously, there are hydrogen bond forms between the $(R)$-Boc-nipecotic acid towards $h$ AChE-sarin complex residues involving Phe295 and Tyr341.

\section{CONCLUSIONS}

This study provides information to determine the potential reactivators for sarin-inhibited $\mathrm{AChE}$ based on the possible distance of the nucleophilic attack of $\mathrm{O}$ from the reactivator towards P from the sarin. ( $R$ )-Boc-nipecotic acid shows shorter nucleophilic attack distance and high binding affinity implying that this compound could be an alternative antidote towards sarin inhibited- $h$ AChE. Despite the commercial charged oxime, 2-PAM, which might present better nucleophilicity towards sarin-inhibited AChE, the uncharged $(R)$-Bocnipecotic acid is presumed to penetrate the blood-brain barrier and worth to be proven experimentally. It is hoped that these data should be beneficial in assessing new antidote candidates for nerve agent poisoning. 
Rauda A. Mohamed, Keat Khim Ong, Norhana Abdul Halim, Noor Azilah Mohd Kasim, Siti Aminah Mohd Noor, Victor Feizal Knight, Rabbani Muhamad and Wan Md Zin Wan Yunus

\section{ACKNOWLEDGMENTS}

This research was supported by the Ministry of Education under Grant UPNM/2018/ CHEMDEF/ST/01. The authors acknowledge Prof. Madya Dr. Adam Leow Thean Chor from the Department of Cell and Molecular Biology, Faculty of Biotechnology and Biomolecular Sciences Universiti Putra Malaysia for the YASARA software.

\section{REFERENCES}

Abou-Donia, M. B., Siracuse, B., Gupta, N., \& Sokol, A. S. (2016). Sarin (GB, O isopropyl methylphosphonofluoridate) neurotoxicity: Critical review. Critical Reviews in Toxicology, 46(10), 845875. https://doi.org/10.1080/10408444.2016.1220916

Ajami, D., \& Rebek, J. (2013). Chemical approaches for detection and destruction of nerve agents. Organic and Biomolecular Chemistry, 11(24), 3936-3942. https://doi.org/10.1039/c3ob40324f

Artursson, E., Akfur, C., Hornberg, A., Worek, F., \& Ekstrom, F. (2009). Reactivation of tabun-hAChE investigated by structurally analogous oximes and mutagenesis. Toxicology, 265(3), 108-114. https:// doi.org/10.1016/j.tox.2009.09.002

Bagaria, A., Jaravine, V., Huang, Y. J., Montelione, G. T., \& Guntert, P. (2012). Protein structure validation by generalized linear model root-mean-square deviation prediction. Protein Science, 21(2), 229-238. https://doi.org/10.1002/pro.2007

Baker, S. R. (1990). The effects of pesticides on human health. In C. F. Wilkinson (Ed.), Advances in modern environmental toxicology (pp. 35-130). Princeton Scientific Publication.

Barak, D., Kronman, C., Ordentlich, A., Ariel, N., Bromberg, A., Marcus, D., Lazara, A., Velan, B., \& Shafferman, A. (1994). Acetylcholinesterase peripheral anionic site degeneracy conferred by amino acid arrays sharing a common core. Journal of Biological Chemistry, 269(9), 6296-6305. https://doi. org/10.1016/S0021-9258(17)37371-4

Baweja, M., Singh, P. K., Sadaf, A., Tiwari, R., Nain, L., Khare, S. K., \& Shukla, P. (2017). Cost effective characterization process and molecular dynamic simulation of detergent compatible alkaline protease from Bacillus pumilus strain MP27. Process Biochemistry, 58, 199-203. https://doi.org/10.1016/j. procbio.2017.04.024

Bhattacharjee, A. K., Marek, E., Le, H. T., Ratcliffe, R., DeMar, J. C., Pervitsky, D., \& Gordon, R. K. (2015). Discovery of non-oxime reactivators using an in silico pharmacophore model of reactivators for DFPinhibited acetylcholinesterase. European Journal of Medicinal Chemistry, 90, 209-220. https://doi. org/10.1016/j.ejmech.2014.11.013

Brighente, I. M. C., \& Yunes, R. A. (1997). The general mechanisms of attack of nitrogen nucleophiles on carbonyl compounds. Facts that determine the change of the rate-pH profiles. Journal of the Brazillian Chemical Society, 8(5), 549-553. d https://doi.org/10.1590/S0103-50531997000500018

Cadieux, C. L., Wang, H., Zhang, Y., Koenig, J. A., Shih, T. M., McDonough, J., Koh, J., \& Cerasoli, D. (2016). Probing the activity of a non-oxime reactivator for acetylcholinesterase inhibited by organophosphorus nerve agents. Chemico-Biological Interactions, 259(Pt B), 133-141. https://doi.org/10.1016/j. cbi.2016.04.002 
Chen, D. E., Willick, D. L., Ruckel, J. B., \& Floriano, W. B. (2015). Principal component analysis of binding energies for single-point mutants of hT2R16 bound to an agonist correlate with experimental mutant cell response. Journal of Computational Biology, 22(1), 37-53. https://doi.org/10.1089/cmb.2014.0192

Colovic, M. B., Krstic, D. Z., Lazarevic-Pasti, T. D., Bondzic, A. M., \& Vasic, V. M. (2013). Acetylcholinesterase inhibitors: Pharmacology and toxicology. Current Neuropharmacology, 11(3), 315-335. https://doi. org/10.2174/1570159x11311030006

de Almeida, J. S. F. D., Guizado, T. R. C., Guimarães, A. P., Ramalho, T. C., Gonçalves, A. S., de Koning, M. C., \& França, T. C. C. (2016). Docking and molecular dynamics studies of peripheral site ligand-oximes as reactivators of sarin-inhibited human acetylcholinesterase. Journal of Biomolecular Structure and Dynamics, 34(12), 1-11. https://doi.org/10.1080/07391102.2015.1124807

de Koning, M. C., Horn, G., Worek, F., \& Grol, M. V. (2018). Discovery of a potent non-oxime reactivator of nerve agent inhibited human acetylcholinesterase. European Journal of Medicinal Chemistry, 157, 151-160. https://doi.org/10.1016/j.ejmech.2018.08.016

de Koning, M. C., Joosen, M. J. A., Worek, F., Nachon, F., van Grol, M., Klaassen, S. D., Alkema, D. P. W., Wille, T., \& de Bruijn, H. M. (2017). Application of the Ugi multicomponent reaction in the synthesis of reactivators of nerve agent inhibited Acetylcholinesterase. Journal of Medicinal Chemistry, 60(22), 9376-9392. https://doi.org/10.1021/acs.jmedchem.7b01083

de Koning, M. C., van Grol, M., \& Noort, D. (2011). Peripheral site ligand conjugation to a non-quaternary oxime enhances reactivation of nerve agent-inhibited human acetylcholinesterase. Toxicology Letters, 206(1), 54-59. https://doi.org/10.1016/j.toxlet.2011.04.004

de Souza, F. R., Garcia, D. R., Cuya, T., Pimentel, A. S., Gonçalves, A. S., de Alencastro, R. B., \& França, T. C. C. (2020). Molecular modeling study of uncharged oximes compared to HI-6 and 2-PAM inside human AChE sarin and VX conjugates. American Chemical Society Omega, 5(9), 4490-4500. https:// doi.org/10.1021/acsomega.9b03737

Duan, Y., Wu, C., Chowdhury, S., Lee, M. C., Xiong, G., Zhang, W., Yang, R., Cieplak, P., Luo, R., Lee, T., Caldwell, J., Wang, J., \& Kollman, P. (2003). A point-charge force field for molecular mechanics simulations of proteins based on condensed-phase quantum mechanical calculations. Journal of Computational Chemistry, 24(16), 1999-2012. https://doi.org/10.1002/jcc.10349

Ishak, S. N. H., Aris, S. N. A. M., Halim, K. B. A., Ali, M. S. M., Leow, T. C., Kamarudin, N. H. A., Masomian, M., \& Rahman, R. N. Z. R. A. (2017). Molecular dynamic simulation of space and earth-grown crystal structures of thermostable T1 lipase Geobacillus zalihae revealed a better structure. Molecules, 22(10), Article 1574. https://doi.org/10.3390/molecules22101574

Johnson, G., \& Moore, S. (2006). The peripheral anionic site of acetylcholinesterase: structure, functions and potential role in rational drug design. Current Pharmaceutical Design, 12(2), 217-225. https://doi. org/10.2174/138161206775193127

Katz, F. S., Pecic, S., Schneider, L., Zhu, Z., Hastings-Robinson, A., Luzac, M., Macdonald, J., Landry, D. W., \& Stojanovic, M. N. (2018). New therapeutic approaches and novel alternatives for organophosphate toxicity. Toxicology Letters, 291, 1-10. https://doi.org/10.1016/j.toxlet.2018.03.028 
Rauda A. Mohamed, Keat Khim Ong, Norhana Abdul Halim, Noor Azilah Mohd Kasim, Siti Aminah Mohd Noor, Victor Feizal Knight, Rabbani Muhamad and Wan Md Zin Wan Yunus

Katz, F. S., Pecic, S., Tran, T. H., Trakht, I., Schneider, L., Zhu, Z., Ton-That, L., Luzac, M., Zlatanic, V., Damera, S., Macdonald, J., Landry, D. W., Tong, L., \& Stojanovic, M. N. (2015). Discovery of new classes of compounds that reactivate acetylcholinesterase inhibited by organophosphates. ChemBioChem, 16(15), 2205-2215. https://doi.org/10.1002/cbic.201500348

Kim, S., Thiessen, P. A., Bolton, E. E., Chen, J., Fu, G., Gindulyte, A., Han, L., He, J., He, S., Shoemaker, B. A., Wang, J., Yu, B., Zhang, J., \& Bryant, S. H. (2016). PubChem substance and compound databases. Nucleic Acids Research, 44(D1), D1202-D1213. https://doi.org/10.1093/nar/gkv951

Konagurthu, A. S., Whisstock, J. C., Stuckey, P. J., \& Lesk, A. M. (2006). MUSTANG: A multiple structural alignment algorithm. Proteins: Structure, Function, and Bioinformatics, 64(3), 559-574. https://doi. org/10.1002/prot.20921

Kovarik, Z., MačEk, N., Sit, R. K., Radić, Z., Fokin, V. V., Sharpless, K., \& Taylor, P. (2013). Centrally acting oximes in reactivation of tabun-phosphoramidated AChE. Chemico-Biological Interactions, 203(1), 77 80. https://doi.org/10.1016/j.cbi.2012.08.019

Krieger, E., Koraimann, G., \& Vriend, G. (2002). Increasing the precision of comparative models with YASARA NOVA-A self-parameterizing force field. Proteins, 47(3), 393-402. https://doi.org/10.1002/prot.10104

Krieger, E., \& Vriend, G. (2014). YASARA View - molecular graphics for all devices - from smartphones to workstations. Bioinformatics, 30(20), 2981-2982. https://doi.org/10.1093/bioinformatics/btu426

Kryger, G., Harel, M., Giles, K., Toker, L., Velan, B., Lazar, A., Kronman, C., Barak, D., Ariel, N., Shafferman, A., Silman, I., \& Sussman, J. L. (2000). Structures of recombinant native and E202Q mutant human acetylcholinesterase complexed with the snake-venom toxin fasciculin-II. Acta Crystallographica Section D: Biological Crystallography, 56(11), 1385-1394. https://doi.org/10.1107/S0907444900010659

Kuca, K., Musilek, K., Jun, D., Karasova, J., Soukup, O., Pejchal, J., \& Hrabinova, M. (2013). Structureactivity relationship for the reactivators of acetylcholinesterase inhibited by nerve agent VX. Medicinal Chemistry, 9(5), 689-693. https://doi.org/10.2174/1573406411309050008

Lotti, M. (2010). Clinical toxicology of anticholinesterase agents in humans. In R. Krieger (Ed.), Hayes' Handbook of Pesticide Toxicology (pp. 1543-1589). Elsevier Inc.

Mallender, W. D., Szegletes, T., \& Rosenberry, T. L. (2000). Acetylthiocholine binds to Asp74 at the peripheral site of human acetylcholinesterase as the first step in the catalytic pathway. Biochemistry, 39(26), 77537763. https://doi.org/10.1021/bi000210o

Matos, K. S., Mancini, D. T., da Cunha, E. F. F., Kuca, K., Franca, T. C. C., \& Ramalho, T. C. (2011). Molecular aspects of the reactivation process of acetylcholinesterase inhibited by cyclosarin. Journal of Brazilian Chemistry Society, 22(10), 1999-2004.

Mercey, G., Renou, J., Verdelet, T., Kliachyna, M., Baati, R., Gillon, E., Arboleas, M., Loiodice, M., Nachon, F., Jean, L., \& Renard, P. Y. (2012a). Phenyltetrahydroisoquinoline-pyridinaldoxime conjugates as efficient uncharged reactivators for the dephosphylation of inhibited human acetylcholinesterase. Journal of Medicinal Chemistry, 55(23), 10791-10795. https://doi.org/10.1021/jm3015519

Mercey, G., Verdelet, T., Renou, J., Kliachyna, M., Baati, R., Nachon, F., Jean, L., \& Renard, P. Y. (2012b). Reactivators of acetylcholinesterase inhibited by organophosphorus nerve agents. Accounts of Chemical Research, 45(5), 756-766. https://doi.org/10.1021/ar2002864 
Morris, G. M., Goodsell, D. S., Halliday, R. S., Huey, R., Hart, W. E., Belew, R. K., \& Olson, A. J. (1998). Automated docking using a Lamarckian genetic algorithm and an empirical binding free energy function. Journal of Computational Chemistry, 19(14), 1639-1662. d https://doi.org/10.1002/(SICI)1096987X(19981115)19:14<1639::AID-JCC10>3.0.CO;2-B

Mukherjee, S., \& Bahadur, R. P. (2018). An account of solvent accessibility in protein-RNA recognition. Scientific Reports, 8(1), 1-13. https://doi.org/10.1038/s41598-018-28373-2

Musilek, K., Jun, D., Cabal, J., Kassa, J., Gunn-Moore, F., \& Kuca, K. (2007). Design of a potent reactivator of tabun-inhibited acetylcholinesterases-synthesis and evaluation of (E)-1-(4-carbamoylpyridinium)-4-(4hydroxyiminomethylpyridinium)-but-2-ene dibromide (K203). Journal of Medicinal Chemistry, 50(22), 5514-5518.https://doi.org/10.1021/jm070653r

Namba, T., Nolte, C. T., Jackrel, J., \& Grob, D. (1971). Poisoning due to organophosphate insecticides. Acute and chronic manifestations. The American Journal of Medicine, 50(4), 475-492. https://doi. org/10.1016/0002-9343(71)90337-8

Ordentlich, A., Barak, D., Sod-Moriah, G., Kaplan, D., Mizrahi, D., Segall, Y., Kronman, C., Karton, Y., Lazar, A., Marcus, D., Velan, B., \& Shafferman, A. (2004). Stereoselectivity toward VX is determined by interactions with residues of the acyl pocket as well as of the peripheral anionic site of AChE. Biochemistry, 43(35), 11255-11265. https://doi.org/10.1021/bi0490946

Patil, N., Ranjan, A., Chauhan, A., \& Jindal, T. (2018). Mechanistic of organophosphate mediated inhibition of human acetylcholinesterase by molecular docking. JSM Bioinformatics, Genomics and Proteomics, 3(2), 1032-1040.

Qiao, Y., Han, K., \& Zhan, C. G. (2014). Reaction pathways and free energy profiles for cholinesterase-catalyzed hydrolysis of 6-monoacetylmorphine. Organic and Biomolecular Chemistry, 12(14), 2214-2227. https:// doi.org/10.1039/c3ob42464b

Radić, Z., Sit, R. K., Garcia, E., Zhang, L., Berend, S., Kovarik, Z., Amitai, G., Fokin, V. V., Sharpless, K. B., \& Taylor, P. (2013). Mechanism of interaction of novel uncharged, centrally active reactivators with OP-hAChE conjugates. Chemico-Biological Interactions, 203(1), 67-71. https://doi.org/10.1016/j. cbi.2012.08.014

Radić, Z., Sit, R. K., Kovarik, Z., Berend, S., Garcia, E., Zhang, L., Amitai, G., Green, C., Radic, B., Fokin, V. V., Sharpless K. B., \& Taylor, P. (2012). Refinement of structural leads for centrally acting oxime reactivators of phosphylated cholinesterases. Journal of Biological Chemistry, 287(15), 11798-11809. https://doi.org/10.1074/jbc.M111.333732

Ranjan, A., Kumar, A., Gulati, K., Thakur, S., \& Jindal, T. (2015). Role of aromatic amino acids in stabilizing organophosphate and human acetylcholinesterase complex. Journal of Current Pharma Research, 5(4), 1632-1639. https://doi.org/10.33786/JCPR.2015.V05I04.006

Schaeffer, L. (2008). The role of functional groups in drug-receptor interactions. In C.G. Wermuth, P. Raboisson, D. Aldous, \& D. Rognan (Eds.), The practice of medicinal chemistry (pp. 359-378). Elsevier Incorporation. https://doi.org/10.1016/B978-0-12-417205-0.00014-6

Shafferman, A., Velan, B., Ordentlich, A., Kronman, C., Grosfeld, H., Leitner, M., Flashner, Y., Cohen, S., Barak, D., \& Ariel, N. (1992). Substrate inhibition of acetylcholinesterase: Residues affecting signal 
Rauda A. Mohamed, Keat Khim Ong, Norhana Abdul Halim, Noor Azilah Mohd Kasim, Siti Aminah Mohd Noor, Victor Feizal Knight, Rabbani Muhamad and Wan Md Zin Wan Yunus

transduction from the surface to the catalytic center. European Molecular Biology Organization Journal, 11(10), 3561-3568. https://doi.org/10.1002/j.1460-2075.1992.tb05439.x

Sit, R. K., Radić, Z., Gerardi, V., Zhang, L., Garcia, E., Katalinić, M., Amitai, G., Kovarik, Z., Fokin, V. V., Sharpless, K. B., \& Taylor, P. (2011). New structural scaffolds for centrally acting oxime reactivators of phosphylated cholinesterases. Journal of Biological Chemistry, 286(22), 19422-19430. https://doi. org/10.1074/jbc.M111.230656

Tang, M., Zhou, Y., Xu, W., Li, S., Wang, L., Wei, D., \& Qiao, Z. (2013). A novel drug candidate for Alzheimer's disease treatment: Gx-50 derived from Zanthoxylum bungeanum. Journal of Alzheimer's Disease, 34(1), 203-213. https://doi.org/10.3233/JAD-121831

Wlodek, S. T., Shen, T., \& McCammon, J. A. (2000). Electrostatic steering of substrate to acetylcholinesterase: Analysis of field fluctuations. Biopolymers, 53(3), 265-271. https://doi.org/10.1002/(SICI)10970282(200003)53:3<265::AID-BIP6>3.0.CO;2-N

Yellapu, N., Gopal, J., Thulasibabu, R., Gunasekaran, K., \& Jambulingam, P. (2015). Screening and identification of inhibitors against glutathione synthetase, a potential drug target of Plasmodium falciparum. Combinatorial Chemistry \& High Throughput Screening, 18, $492-504$.

Zhang, Y., Zhang, S., Xu, G., Yan, H., Pu, Y., \& Zuo, Z. (2016). The discovery of new acetylcholinesterase inhibitors derived from pharmacophore modeling, virtual screening, docking simulation and bioassays. Molecular BioSystems, 12(12), 3734-3742. https://doi.org/10.1039/C6MB00661B 